Short Communication

\title{
Preparation of Phosphate Ion-Selective Membrane Based on Silver Salts Mixed with PTFE or Carbon Nanotubes
}

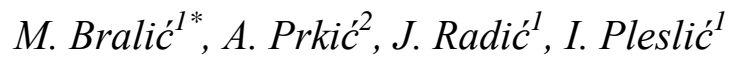 \\ ${ }^{1}$ Department of Environmental Chemistry, Faculty of Chemistry and Technology, R. Boškovića 35, \\ 21000 Split, Croatia \\ ${ }^{2}$ Department of Analytical Chemistry, Faculty of Chemistry and Technology, R. Boškovića 35, 21000 \\ Split, Croatia \\ *E-mail: bralic@ktf-split.hr
}

doi: $10.20964 / 2018.02 .49$

Received: 14 November 2017 / Accepted: 13 December 2017 / Published: 28 December 2017

\begin{abstract}
A sensitive phosphate sensor has been prepared by constructing a solid membrane disk consisting of variable mixtures of silver phosphate, silver sulfide, and PTFE (Type 1 membrane) or silver phosphate, silver sulfide and nanotube (Type 2 membrane). The ternary membranes exhibit greater selectivity over the wide range of concentration. The membrane with the composition of $50.00 \%$ PTFE; $41.66 \%$ $\mathrm{Ag}_{3} \mathrm{PO}_{4}$ and $8.33 \% \quad \mathrm{Ag}_{2} \mathrm{~S}$ was selected as our preferred membrane. The membranes exhibited linear potential response in the concentration range of $1 \times 10^{-1}$ to $1 \times 10^{-5} \mathrm{M}$. Their detection limit is about $5 \times 10^{-6} \mathrm{M}$. The membranes have a long lifetime and can be stored in air when they are not in use. The best performance for nanocomposite sensor was obtained with membrane of the following composition: $78.00 \% \mathrm{Ag}_{3} \mathrm{PO}_{4} ; 20.00 \% \mathrm{Ag}_{2} \mathrm{~S}$, and $2.00 \%$ carbon nanoparticles. The membrane had a slope of $32.6 \mathrm{mV}$ toward $\mathrm{HPO}_{4}{ }^{2-}$ ions in the range between $1 \times 10^{-1}$ and $1 \times 10^{-5} \mathrm{M}$ with a detection limit of $5.45 \times 10^{-6} \mathrm{M}$. The proposed sensors were found to be applicable over a $\mathrm{pH}$ range between 3 and 7 .
\end{abstract}

Keywords: ion selective electrode, monohydrogen phosphate, potentiometry, carbon nanotubes, PTFE.

\section{FULL TEXT}

(C) 2018 The Authors. Published by ESG (www.electrochemsci.org). This article is an open access article distributed under the terms and conditions of the Creative Commons Attribution license (http://creativecommons.org/licenses/by/4.0/). 